\title{
Padrões dinâmicos de transporte e migração do zooplâncton, com ênfase nos Decapoda planctônicos, da Barra de Catuama, Pernambuco, Brasil
}

\author{
Mauro de Melo Júnior
}

\section{Resumo}

Estudos sobre o fluxo de zooplâncton entre o Canal de Santa Cruz (CSC) - a partir da Barra de Catuama - e a plataforma costeira adjacente (PCA) foram feitos com o objetivo de quantificar essa troca e definir os mecanismos de transporte e migração dos Decapoda planctônicos. As coletas foram realizadas durante as marés de sizígia (05 e 06/08/2001) e de quadratura (11 e 12/08/2001), em intervalos de 3 horas, num período de 15 horas para a maré de sizígia ( $\mathrm{n}=32$ amostras) e de 24 horas para a maré de quadratura ( $\mathrm{n}=56$ amostras). As amostras foram coletadas em três estações fixas (Estações Meio ou Convergência, Continente e Ilha) e em três níveis de profundidades (superfície, meio e fundo). Com o auxílio de uma bomba de sucção, a água foi filtrada com rede de plâncton (300 $\mu \mathrm{m})$, durante 3 a 5 minutos. Logo após a filtragem, o material foi fixado com formol a $4 \%$, neutralizado com bórax. Simultaneamente às coletas biológicas, foram feitas medições de velocidade e direção de corrente, através de um perfilador acústico de corrente (ADCP), além de temperatura, salinidade e oxigênio dissolvido. Em laboratório, as amostras foram pesadas, em balança de precisão, para determinação da biomassa sestônica através do peso úmido. Para a análise dos organismos, cada amostra foi totalmente analisada em estereomicroscópio. A Barra de Catuama apresentou uma grande variabilidade nos dados de biomassa sestônica e zooplâncton, com valores relativamente elevados, sobretudo durante a sizígia. O transporte instantâneo médio da biomassa foi de $98.10 \pm 75.92 \mathrm{mg} \cdot \mathrm{m}^{-2} . \mathrm{s}^{-1}$, durante a sizígia, e de $31.46 \pm 26.52 \mathrm{mg} \cdot \mathrm{m}^{-2} . \mathrm{s}^{-1}$, durante a quadratura. Os maiores picos de transporte de biomassa estiveram associados a grandes densidades de Brachyura, Calanoida e Sergestoida. Quanto ao transporte médio de organismos, os valores foram de 831.47 \pm 1192.53 org. $\mathrm{m}^{-2} \cdot \mathrm{s}^{-1}$, durante a sizígia, e de $342.33 \pm 445.80 \mathrm{org} . \mathrm{m}^{-2} \cdot \mathrm{s}^{-1}$, durante a quadratura. Os maiores valores de transporte de biomassa e organismos foram observados durante o período noturno (enchente e vazante). Os fluxos de importação e exportação não apresentaram diferenças significativas $(p>0,05)$, sugerindo que em determinados períodos os valores podem possuir uma mesma ordem de magnitude. Provavelmente, estes dados podem ser em decorrência da forte influência marinha existente na área estudada, ocorrência de frentes estuarinas dentro do CSC, época de baixa liberação de larvas e forte impacto de peixes planctívoros sobre o meroplâncton. A análise estatística mostrou acúmulos significativos de zooplâncton nas zonas de convergência apenas durante o período diurno $(\mathrm{p}<0,05)$, considerando as três estações, refletindo que durante a noite, além das zonas de convergência, alguns taxa utilizam outros mecanismos de transporte. Foram identificados 29 taxa de Decapoda planctônicos, destacando-se os estágios iniciais de Lucifer faxoni, Acetes americanus, Pinnixa spp., Ocypodidae Morfotipo A, Uca spp., Petrolisthes armatus, Upogebia spp. e Alpheidae. A maior parte dos taxa registrados possui migração vertical em sincronia com as fases de maré e o fotoperíodo. O CSC atua, provavelmente, como área de reprodução para os Sergestoida, já que foi detectado um importante fluxo (tanto de importação quanto de exportação), de todos os estágios de desenvolvimento deste grupo. A função dos estuários tropicais como fonte de larvas de Decapoda do CSC para áreas costeiras foi confirmada no presente estudo. Os dados apresentados mostram que larvas de Decapoda são exportadas do CSC para a PCA, mas o elevado número de estágios iniciais em grande parte dos taxa identificados sugere que o desenvolvimento destas espécies ocorre na região próxima à Barra de Catuama.

Palavras-chave: zooplâncton; larvas de Decapoda; região estuarina; ciclo de marés; estratégias de exportação e retenção; ADCP 
Melo Júnior, Mauro de

Padrões dinâmicos de transporte e migração do zooplâncton, com ênfase nos Decapoda planctônicos, da Barra de Catuama, Pernambuco -Brasil / Mauro de Melo Júnior. - Recife : O Autor, 2005.

xviii, 123 folhas : il., fig., gráf., tab., quadros, mapas, fotos. Dissertação (mestrado) - Universidade Federal de Pernambuco. CTG. Oceanografia Biológica, 2005.

Inclui bibliografia e apêndices.

1. Oceanografia biológica - Zooplâncton. 2. Decapoda planctônicos - Transporte e migração vertical - Estuários - Barra de Catuama, Itamaracá, PE. 3. Larvas de Decapoda - Estratégias de exportação e retenção. I. Título.

594.58 CDU (2.ed.) UFPE

595.38 CDU (22.ed.) BC2005-115 